\title{
Antiglycation, radical scavenging, and semicarbazide-sensitive amine oxidase inhibitory activities of acetohydroxamic acid in vitro
}

This article was published in the following Dove Press journal:

Drug Design, Development and Therapy

13 July 2017

Number of times this article has been viewed

\author{
Yuh-Hwa Liu' ${ }^{1,2, *}$ \\ Yeh-Lin Lu ${ }^{3, *}$ \\ Der-Zen $\mathrm{Liu}^{4}$ \\ Wen-Chi Hou ${ }^{5}$
}

'Division of Gastroenterology, Shin Kong Wu Ho-Su Memorial Hospital, Taipei, Taiwan; ${ }^{2}$ Department of General Medicine, College of Medicine, Taipei Medical University, Taipei, Taiwan; ${ }^{3}$ Department of Pharmacy, Taipei Medical University, Taipei, Taiwan; ${ }^{4}$ Graduate Institute of Biomedical Materials and Tissue Engineering, Taipei Medical University, Taipei, Taiwan; ${ }^{5} \mathrm{G}$ raduate Institute of Pharmacognosy, Taipei Medical University, Taipei, Taiwan

*These authors contributed equally to this work
Correspondence: Wen-Chi Hou Graduate Institute of Pharmacognosy, Taipei Medical University, No 250, Wu-Hsing Street, Taipei I I0, Taiwan Tel +88622736 I66I ext 6160 Fax +886223780134 Email wchou@tmu.edu.tw

\begin{abstract}
Advanced glycation endproducts (AGEs) can promote intracellular reactive oxygen species production, and the levels of AGEs are highly correlated with cardiovascular disease and diabetes complications. Acetohydroxamic acid (acetH) is a bacterial urease inhibitor drug used to treat kidney stones and infections in the urinary tract, and hydroxyurea (HU) is a drug used for antineoplasm and sickle cell diseases. Both acetH and $\mathrm{HU}$ are hydroxamic acid derivatives. It was found that acetH and $\mathrm{HU}$ at 2.5 or $5 \mathrm{mM}$ showed anti-AGE formation by lowering the AGEs' fluorescent intensities and $\mathrm{N}^{\varepsilon}$-(carboxymethyl)lysine formation in bovine serum albumin/ galactose models, and both showed better and significant differences $(P<0.05)$ compared to the positive control of aminoguanidine. Regarding radical scavenging activities, the half-inhibition concentrations $\left(\mathrm{IC}_{50}\right)$ of acetH against $\alpha, \alpha$-diphenyl- $\beta$-picrylhydrazyl radical and hydroxyl radical were 34.86 and $104.42 \mu \mathrm{M}$, respectively. The $\mathrm{IC}_{50}$ of acetH against semicarbazide-sensitive amine oxidase was $10.56 \mu \mathrm{M}$, and acetH showed noncompetitive inhibition respective to the substrates (benzylamine). The antiglycation, antioxidant, and semicarbazide-sensitive amine oxidase inhibitory activities of acetH prove that it has the potential for treating cardiovascular disease and diabetes complications and it needs further investigation in animal models.
\end{abstract}

Keywords: acetH, AGEs, $\mathrm{N}^{\varepsilon}$-(carboxymethyl)lysine, semicarbazide-sensitive amine oxidase, SSAO

\section{Introduction}

Reactive oxygen species (ROS), such as radicals of superoxide anion radicals $\left(\mathrm{O}_{2} \cdot{ }^{-}\right)$ and hydroxyl radicals ( $\mathrm{OH} \cdot)$ and nonradicals of lipid peroxides $(\mathrm{LOOH})$ and hydrogen peroxide $\left(\mathrm{H}_{2} \mathrm{O}_{2}\right)$, are associated with normal aging, cardiovascular diseases, and neurodegenerative diseases. ${ }^{1,2}$ The UV radiation may increase the intracellular ROS levels resulting in more production than elimination, which may lead to oxidative stress in cells. ${ }^{3}$ The intracellular ROS is the byproduct of energy production from the electron transfer chain in the mitochondria or the product of enzymatic reaction (of enzymes such as superoxide dismutase, xanthine oxidase, and amine oxidase). There are many proposed theories to explain the aging process, among which the "free radical theory of aging" focuses on the roles of ROS and related scavenging systems in the cells during the aging process. ${ }^{1,4}$

The Maillard reaction refers to a complex set of chemical reactions between monosaccharides and proteins that occur via nucleophilic attacks, leading to the Schiff base formation, which slowly rearranges to generate Amadori products and advanced glycation end products (AGEs) in the final stages. ${ }^{5-7}$ The AGEs can bind receptors for AGEs to promote intracellular ROS production. ${ }^{8}$ Hemoglobin A1c, 
a well-known nonenzymatic glycation product, is a clinical index for diabetes mellitus, in which the N-terminal amino group of valine is glycated in the hemoglobin $\beta$ chain. Many AGEs, such as $\mathrm{N}^{\varepsilon}$-(carboxymethyl)lysine (CML), have been structurally characterized..$^{5,7}$ The formation and accumulation of AGEs are reported to correlate with cardiovascular disease, ocular diseases, and diabetes complications (such as renal diseases or diabetic dyslipidemia). ${ }^{9-12}$ Several AGE inhibitors are used to delay or inhibit the formation of AGEs. These include guanidine compounds of aminoguanidine (AG) and metformin, which have the capacity to react against Amadori carbonyl compounds, as well as dicarbonyl compounds, which have the capacity to react against protein glycation. $^{11}$

The amine oxidases (AOs) catalyze conversion of several primary amines into the corresponding toxic aldehydes, hydrogen peroxide, and ammonia, which may increase the level of intrinsic ROS in the cells. AOs have been divided into two categories. The first is flavin adenine dinucleotidecontaining AOs, such as monoamine oxidase A, monoamine oxidase $\mathrm{B}$, and polyamine oxidase; the second is coppercontaining semicarbazide-sensitive AOs (SSAO), such as diamine oxidase, soluble AO, and lysyl oxidase. ${ }^{13}$ High levels of plasma SSAO in diabetes mellitus, endothelial damage, and kidney disease have been reported. ${ }^{13-15}$

The chemicals or drugs with hydroxamic acid moiety (R-CONHOH) have been reviewed for biologic and pharmacologic activities in different diseases. ${ }^{16}$ Acetohydroxamic acid (acetH, $\left.\mathrm{CH}_{3} \mathrm{CONHOH}\right)$ is the active drug in Lithostat $^{\circledR}$, which is used to treat urinary tract infections. ${ }^{17}$ Hydroxyurea ( $\mathrm{HU}, \mathrm{NH}_{2} \mathrm{CONHOH}$ ), or hydroxycarbamide,

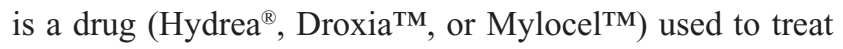
antineoplasm or sickle cell diseases. ${ }^{18}$ AcetH and HU are both hydroxamic acid derivatives. In this study, acetH and HU were used to investigate the effects on antiglycation in bovine serum albumin (BSA)/galactose (Gal) models. AcetH was further used to determine the radical scavenging and SSAO inhibitory activities. It is suggested that the antiglycation, antioxidant, and SSAO inhibitory activities of acetH may have potential for treating diabetes complications, but further investigation is needed.

\section{Materials and methods Materials}

AG, 2,2'-azino-bis(3-ethylbenzothiazoline-6-sulfonic acid), benzylamine, bovine plasma (P-4639), 5,5-dimethyl-1pyrroline-N-oxide (DMPO), $\alpha, \alpha$-diphenyl- $\beta$-picrylhydrazyl (DPPH), ferrous sulfate, Gal, horseradish peroxidase (HRP; 148 units/mg solid), HU, hydrogen peroxide, phosphate-buffered saline (PBS, 10x concentrate), and semicarbazide were obtained from Sigma Chemical Co. (St Louis, MO, USA). AcetH was from Aldrich Co. (St Louis, MO, USA). The Pierce ${ }^{\mathrm{TM}} \mathrm{BSA}$ ampule $(2 \mathrm{mg} / \mathrm{mL})$ was obtained from Thermo Fisher Scientific Inc. (Rockford, IL, USA). The anti-CML antibody (ab27684) was obtained from Abcam Inc. (Cambridge, MA, USA). The HRP-conjugated goat antirabbit IgG (A6154) was from Sigma Chemical Co.

\section{Effects of acetH, HU, or AG on anti- protein glycations in BSA/Gal models} Determination of glycated BSA fluorescence

The BSA/Gal model was used to perform a protein glycation experiment by following the reported methods. ${ }^{19,20}$ One hundred microliters of the solution in the Eppendorf tube contained $20 \mu \mathrm{L}$ of BSA solution $(2 \mathrm{mg} / \mathrm{mL}), 60 \mu \mathrm{L}$ of $1 \mathrm{M}$ Gal solution (in distilled water), $10 \mu \mathrm{L}$ of 10 -fold diluted PBS, and $10 \mu \mathrm{L}$ of acetH, HU, or AG (2.5 or $5 \mathrm{mM}$ in the final concentration) in 10 -fold diluted PBS. Each Eppendorf tube was placed in a $37^{\circ} \mathrm{C}$ water bath in order to perform a nonenzymatic glycation process for 10 or 14 days. BSA-only was the blank and BSA/Gal was the control. The changes in glycated BSA fluorescence with or without the tested compound were determined using the VICTOR ${ }^{\mathrm{TM}} \mathrm{X} 3$ Multilabel Plate Reader (Perkin Elmer Inc., Waltham, MA, USA) at the excitation and emission wavelengths of 355 and $460 \mathrm{~nm}$, respectively.

\section{The CML formations determined by enzyme-linked} immunosorbent assays

The enzyme-linked immunosorbent assay (ELISA) procedure was done following the previous report. ${ }^{19}$ The glycated BSA solution $(5$ or $10 \mu \mathrm{L})$ in a total of $100 \mu \mathrm{L}$ solution was coated onto a 96-well microtiter plate (type F; Nunc MaxiSorp, Roskilde, Denmark) to quantify CML formations. The absorbance was determined at $450 \mathrm{~nm}$ by using an ELISA reader (Sunrise microplate reader; TECAN, Männedorf, Switzerland).

\section{The determination of CML formations in glycated BSA by immune stains}

The glycated BSA were separated by $7.5 \%$ sodium dodecyl sulfate-polyacrylamide gel electrophoresis, and then the gel was transferred onto polyvinylidene difluoride membrane to detect CML formations by immune stains. Each sample solution was mixed with sample buffer (with 2-mercaptoethanol) in 5-fold dilution and heated at $100^{\circ} \mathrm{C}$ for $5 \mathrm{~min}$. After electrophoresis, one gel was stained for proteins using Coomassie Brilliant Blue R-250 and the other gel was 
transferred onto the polyvinylidene difluoride membrane (EMD Millipore, Billerica, MA, USA) following the previous method. ${ }^{21}$ The anti-CML antibody was diluted to 1,667-fold, and the HRP-conjugated secondary antibody was diluted to 100,000-fold. Immunoblots were stained by using Western Chemiluminescent HRP Substrate kits (WBKL S0050, EMD Millipore). The Syngene GeneGnome5 imaging system (Syngene, Cambridge, UK) was used to image the gel of protein stains and the blot of immune stains of each treatment.

\section{Antioxidant and free radical scavenging activity \\ DPPH radical scavenging activity}

The DPPH radical (60 $\mu \mathrm{M}$ in methanol) was used to test acetH $(6,12,24$, and $60 \mu \mathrm{M}$ in distilled water) scavenging activity in $100 \mathrm{mM}$ Tris buffer ( $\mathrm{pH} 7.9) .^{21,22}$ It was placed under light protection at room temperature for $30 \mathrm{~min}$, and the decrease in absorbance at $517 \mathrm{~nm}$ was then measured. Deionized water was used instead of the sample solution as a blank experiment. The decrease of absorbance at $517 \mathrm{~nm}$ was expressed as $\triangle \mathrm{A} 517 \mathrm{~nm}$. The DPPH radical scavenging activity (\%) was calculated using the equation $\left(\Delta \mathrm{A} 517_{\text {blank }}-\Delta \mathrm{A} 517_{\text {sample }}\right) / \Delta \mathrm{A} 517_{\text {blank }} \times 100 \%$. The relationships between the calculated DPPH radical scavenging activities and the acetH concentrations used were transformed into a new equation which was used to calculate the acetH concentration for $50 \%$ radical scavenging activity $\left(\mathrm{IC}_{50}\right)$.

\section{Hydroxyl radical scavenging activities}

The hydroxyl radical scavenging activities of acetH $(10 \mu \mathrm{M}$, $20 \mu \mathrm{M}, 500 \mu \mathrm{M}$, and $5 \mathrm{mM}$ ) were determined by electron spin resonance (ESR) spectrometry. ${ }^{20-22}$ The mixture in the quartz cell contained acetH, DMPO (5 mM), and ferrous sulfate $(0.05 \mathrm{mM})$; then hydrogen peroxide $(0.25 \mathrm{mM})$ was added in the final step. Distilled water was used instead of acetH solution for the parallel experiment with the blank. The intensities of the DMPO-OH adduct in the blank were expressed as $100 \%$, and other treatments, calculated relative to the blank $(\%)$, were expressed as the hydroxyl radical scavenging activity (\%). The relationships between calculated hydroxyl radical scavenging activities and the acetH concentrations used were transformed into a new equation which was used to calculate the $\mathrm{IC}_{50}$ for hydroxyl radical scavenging activity.

\section{Determination of SSAO inhibitory activities and kinetic inhibition modes}

The commercial bovine plasma product (P-4639, Sigma Chemical Co.) was reported to contain SSAO activities. ${ }^{18,21,22}$
Therefore, following previous reports, ${ }^{18,21,22}$ the effects of acetH on SSAO inhibitory activities were investigated. The hydrogen peroxide generated was determined by using 2,2'-azino-bis(3-ethylbenzothiazoline-6-sulfonic acid)/HRP systems, and the changes in absorbance at $420 \mathrm{~nm}$ were recorded during $1 \mathrm{~min}$ and expressed as SSAO inhibition (\%). The relationships between the calculated SSAO inhibitory activities and the acetH concentrations used were transformed into a new equation which was used to calculate the $\mathrm{IC}_{50}$ for SSAO inhibition. To determine the effects of acetH $(6.5 \mu \mathrm{M})$ on SSAO kinetic parameters, different concentrations of benzylamine $(0.67,0.8,1,1.33,2$, and $4 \mathrm{mM})$ were used in the Lineweaver-Burk plots.

\section{Statistical analyses}

Data were expressed as mean \pm SD. Multiple group comparisons for AGE fluorescence or CML formations were performed using one-way analysis of variance and the post hoc Tukey's test, and the different alphabets $(2.5 \mathrm{mM}$, uppercase; $5 \mathrm{mM}$, lowercase) marked in each bar with the same concentration were significantly different $(P<0.05)$.

\section{Results and discussion Effects of acetH, HU, or AG on anti- protein glycation in BSA/Gal models}

The AGEs were formed nonenzymatically between the amino groups of proteins ( $\mathrm{N}$-terminal or side chain of amino groups) and the aldehyde groups in sugars and dicarbonyl compounds in vitro and in vivo..$^{5-7}$ The in vitro reactivity of D-galactose was reported to be 4.7-fold compared to that of D-glucose in hemoglobin glycation. ${ }^{23}$ Therefore, in this study, the effects of acetH, HU, or AG on the formation of AGEs were investigated in the BSA/Gal models (Figure 1). This included the changes in AGEs' fluorescence (Figure 1A) and CML formation detected by ELISA (Figure 1B). It was found that both AGEs' fluorescence and CML formation in the BSA/Gal (the control) were significantly increased $(P<0.05)$ compared to the blank in the 10-day reaction, and that acetH, HU, or AG addition $(2.5$ or $5 \mathrm{mM})$ reduced significantly $(P<0.05)$ both AGEs' fluorescence and CML formation compared to the control. The glycated-BSA fluorescence reduced in acetH, HU, and AG treatment (at $5 \mathrm{mM}$ ) from $100 \%$ to $70.27 \%, 68.22 \%$, and $82.82 \%$, respectively, and the order of lowering AGEs'

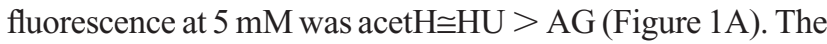
CML formation with acetH, $\mathrm{HU}$, and $\mathrm{AG}$ treatment (at $5 \mathrm{mM}$ ) reduced from $100 \%$ to $14.59 \%, 24.85 \%$, and $49.32 \%$, respectively, and the order of lowering CML formation at $5 \mathrm{mM}$ was acetH $>\mathrm{HU}>\mathrm{AG}$ (Figure 1B). It was clear that both acetH and HU showed better and significant differences $(P<0.05)$ 


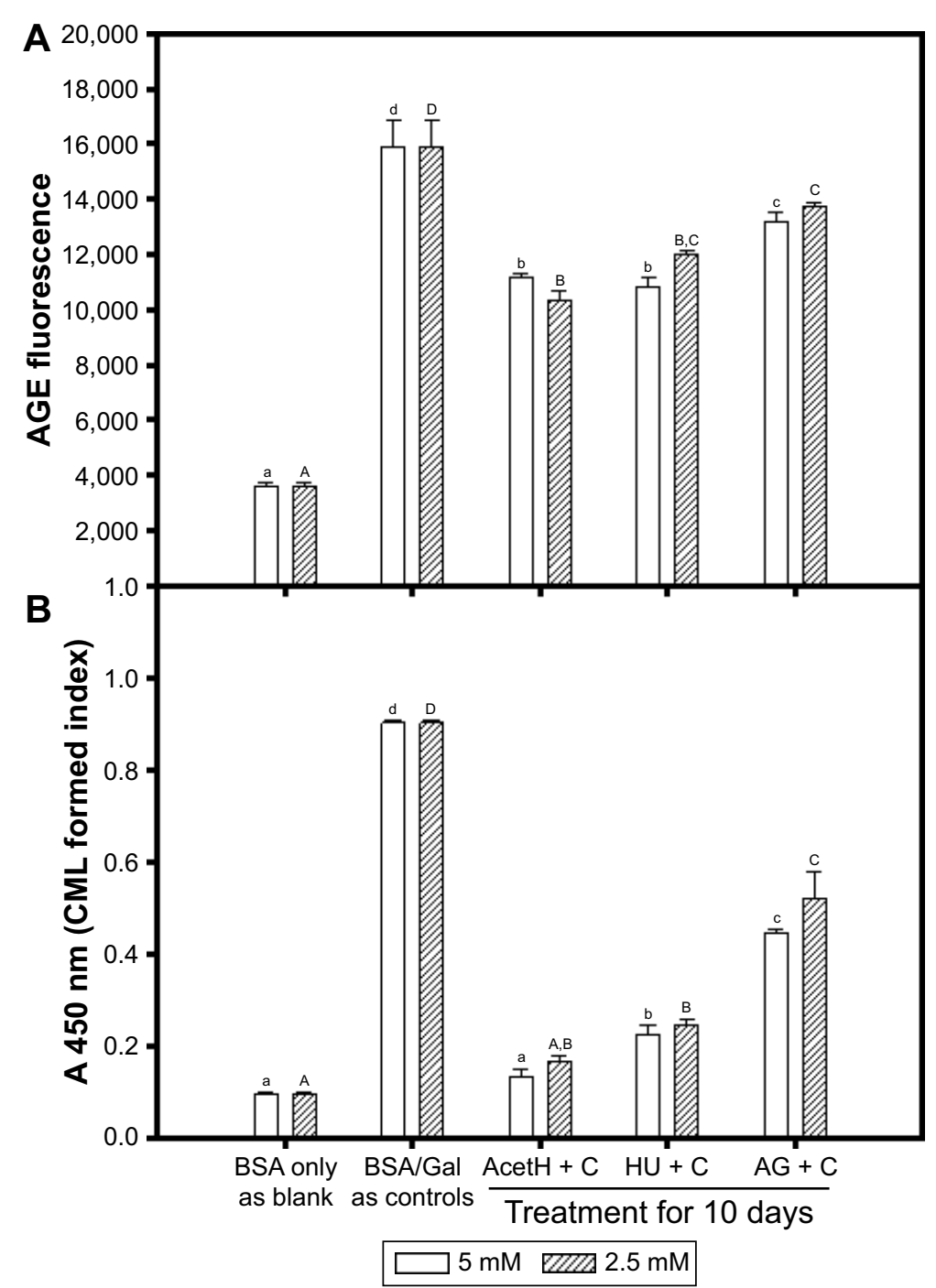

Figure I Effects of different concentrations (2.5 and $5 \mathrm{mM}$ ) of acetH, HU, and AG on (A) AGEs' fluorescence and (B) CML formation detected by ELISA in BSA and Gal models at $37^{\circ} \mathrm{C}$ for 10 days.

Notes: Data were expressed as mean \pm SD. Multiple group comparisons for AGE fluorescence or CML formation were performed using one-way ANOVA and the post hoc Tukey's test, and the different letters $(2.5 \mathrm{mM}$, uppercase; $5 \mathrm{mM}$, lowercase) marked in each bar with the same concentration were significantly different $(P<0.05)$.

Abbreviations: acetH, acetohydroxamic acid; AG, aminoguanidine; AGEs, advanced glycation endproducts; ANOVA, analysis of variance; BSA, bovine serum albumin; $\mathrm{CML}^{\mathrm{E}}$-(carboxymethyl)lysine; ELISA, enzyme-linked immunosorbent assay; Gal, galactose; HU, hydroxyurea.

compared to AG in the reduction of AGE formation in this study. The AG is used to trap carbonyls and dicarbonyl compounds in Amadori intermediates. ${ }^{11,26}$ The AG showed promising antiglycation activities in BSA-glucose, BSA-MGO, and GK dipeptide-ribose models by fluorescence detection. ${ }^{24}$ The fluorescence detection (340-370 nm for excitation and $420-470 \mathrm{~nm}$ for emission) for AGE formation was frequently used in the literature. ${ }^{24,25} \mathrm{ML}$ is one of the well-characterized AGEs; ${ }^{7}$ however, detection of nonfluorescent CML is mainly performed by liquid chromatography-mass spectrometry (LC/MS), ${ }^{27} \mathrm{LC} / \mathrm{MS} / \mathrm{MS},{ }^{28}$ ELISA, and/or immunostains..${ }^{19,20}$ In this study, the fluorescence measurement and detection of CML formation in the BSA/Gal models were done using two independent methods; acetH showed promising antiglycation results and was further used to investigate CML formation by Western blot assays.

Figure 2 shows the immune stains of CML formation with or without $\mathrm{AG}$ and acetH treatment $(5 \mathrm{mM})$ in BSA/Gal models at either 10- or 14-day reaction. The intensities of the protein stains (Figure 2A) did not show an apparent difference among blank (lane 1), control (lane 2), AG (lane 3), and acetH (lane 4) treatment groups under 10-day reaction (left panel, Figure 2A). Similar results (lanes $1^{\prime}-4^{\prime}$ ) were found for the 14-day treated groups (right panel, Figure 2A). Figure 2B shows the Western blot results for CML formation. No detectable CML was found in the blank subjected to either 


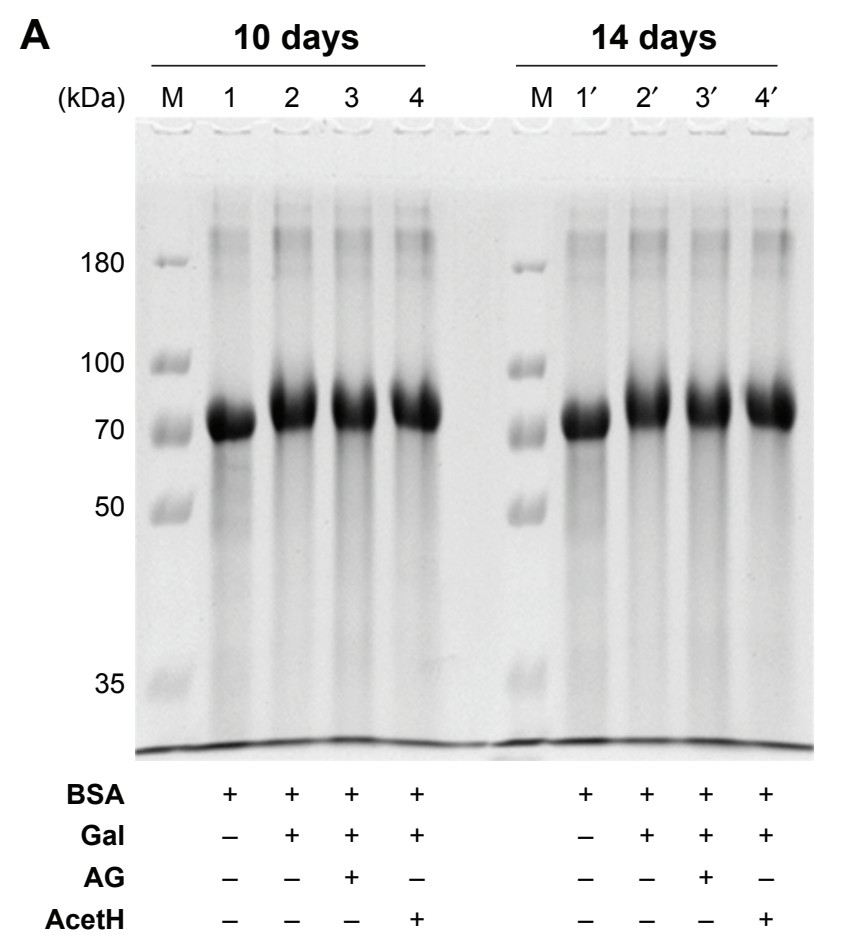

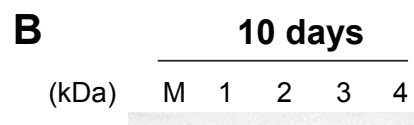
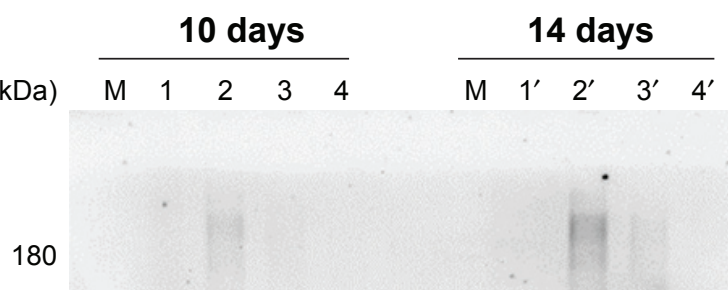

100

70

50

35

$\begin{array}{rllll}\text { BSA } & + & + & + & + \\ \text { Gal } & - & + & + & + \\ \text { AG } & - & - & + & - \\ \text { AcetH } & - & - & - & +\end{array}$
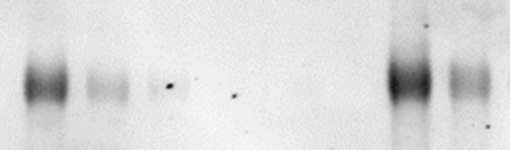

.

Figure 2 (A) The protein stains on the 7.5\% SDS-PAGE gels and (B) the immune stains of CML formation in the PVDF membranes with and without AG and acetH treatment $(5 \mathrm{mM})$ in $\mathrm{BSA} / \mathrm{Gal}$ models at $37^{\circ} \mathrm{C}$ for 10 or 14 days.

Notes: BSA-only was the blank (lanes I and I'); BSA with Gal was the control (lanes 2 and 2'); lanes 3 and 3' show the control + AG treatment; and lanes 4 and 4' show the control + acetH treatment.

Abbreviations: acetH, acetohydroxamic acid; AG, aminoguanidine; BSA, bovine serum albumin; CML, Ne-(carboxymethyl)lysine; Gal, galactose; PVDF, polyvinylidene difluoride; SDS-PAGE, sodium dodecyl sulfate-polyacrylamide gel electrophoresis.

10-day (lane 1) or 14-day (lane 1') reaction; detectable CML was found in the control subjected to both 10-day (lane 2) and 14-day (lane 2 ') reactions, with the latter generating more detectable formation. Under the same protein loads, treatment with $5 \mathrm{mM}$ of AG (lanes 3 and 3') and acetH (lanes 4 and 4') clearly decreased the CML formation, and acetH showed more capacity than $\mathrm{AG}$ in the prevention of CML formation in BSA/Gal models.

\section{Effects of acetH on DPPH and hydroxyl radical scavenging activities}

It was reported that AGEs can induce intracellular ROS production via binding to receptors for AGEs, ${ }^{8}$ and the radical generation was detected by ESR spectrometer in BSA/glucose nonenzymatic glycation models. ${ }^{24}$ Figure 3 shows the scavenging activities of acetH against DPPH radicals and hydroxyl radicals. The stable DPPH radicals were frequently used as the target radicals for evaluation of the scavenging activities of natural or synthesized compounds. ${ }^{29}$ Figure $3 \mathrm{~A}$ shows the DPPH radical scavenging activities of acetH by spectrophotometry. It was found that acetH showed dose-dependent DPPH radical scavenging activities. AcetH at 6, 12, 24, and $60 \mu \mathrm{M}$ showed DPPH radical scavenging activities of $8.8 \%$,
$20.2 \%, 38.0 \%$, and $61.1 \%$, respectively. The relationships between calculated DPPH radical scavenging activities (Y) and the acetH concentrations $(\mathrm{X})$ used were transformed into the equation: $\mathrm{Y}=2.166 \mathrm{X}-3.403-0.018 \mathrm{X}^{2}\left(R^{2}=0.999\right)$. Therefore, the calculated $\mathrm{IC}_{50}$ of acetH for DPPH radical scavenging activity was $34.86 \mu \mathrm{M}$ (Figure 3A), as compared with 13.1 $\mu \mathrm{M}$ for ascorbic acid ${ }^{21,22}$ and $23 \mu \mathrm{M}$ for HU. ${ }^{18}$ Figure $3 \mathrm{~B}$ shows the hydroxyl radical scavenging activities of acetH by ESR spectrometer; the hydroxyl radical is trapped by DMPO and intensities of the DMPO-OH adducts in the blank are recognized as 100. From the results of DMPO-OH intensities, acetH showed dose-dependent scavenging activities against hydroxyl radicals. The $10 \mu \mathrm{M}, 20 \mu \mathrm{M}, 500 \mu \mathrm{M}$, and $5 \mathrm{mM}$ of acetH exhibited hydroxyl radical scavenging activities of $19 \%, 39.8 \%, 63.3 \%$, and $93.5 \%$, respectively. The relationships between calculated hydroxyl radical scavenging activities (Y) and the acetH concentrations used (X, log concentration) were transformed into the equation: $\mathrm{Y}=25.0144 \mathrm{X}-0.4998\left(R^{2}=0.965\right)$. Therefore, the calculated $\mathrm{IC}_{50}$ of acetH for hydroxyl radical scavenging activity was $104.42 \mu \mathrm{M}$ by ESR spectrometry. Electron resonance showed acetH to have two mesomeric forms. ${ }^{29}$ This might explain the radical scavenging activities in this study. 


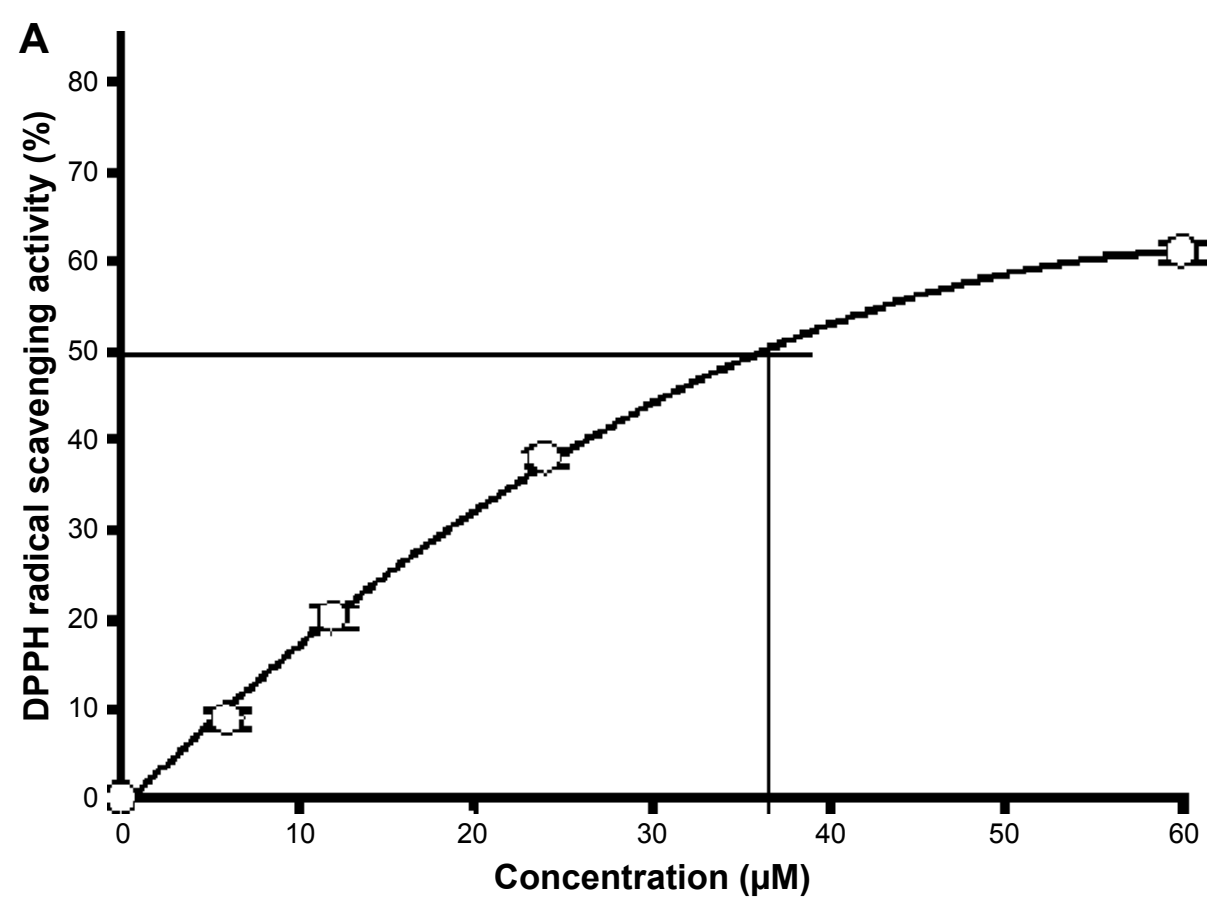

\section{B}
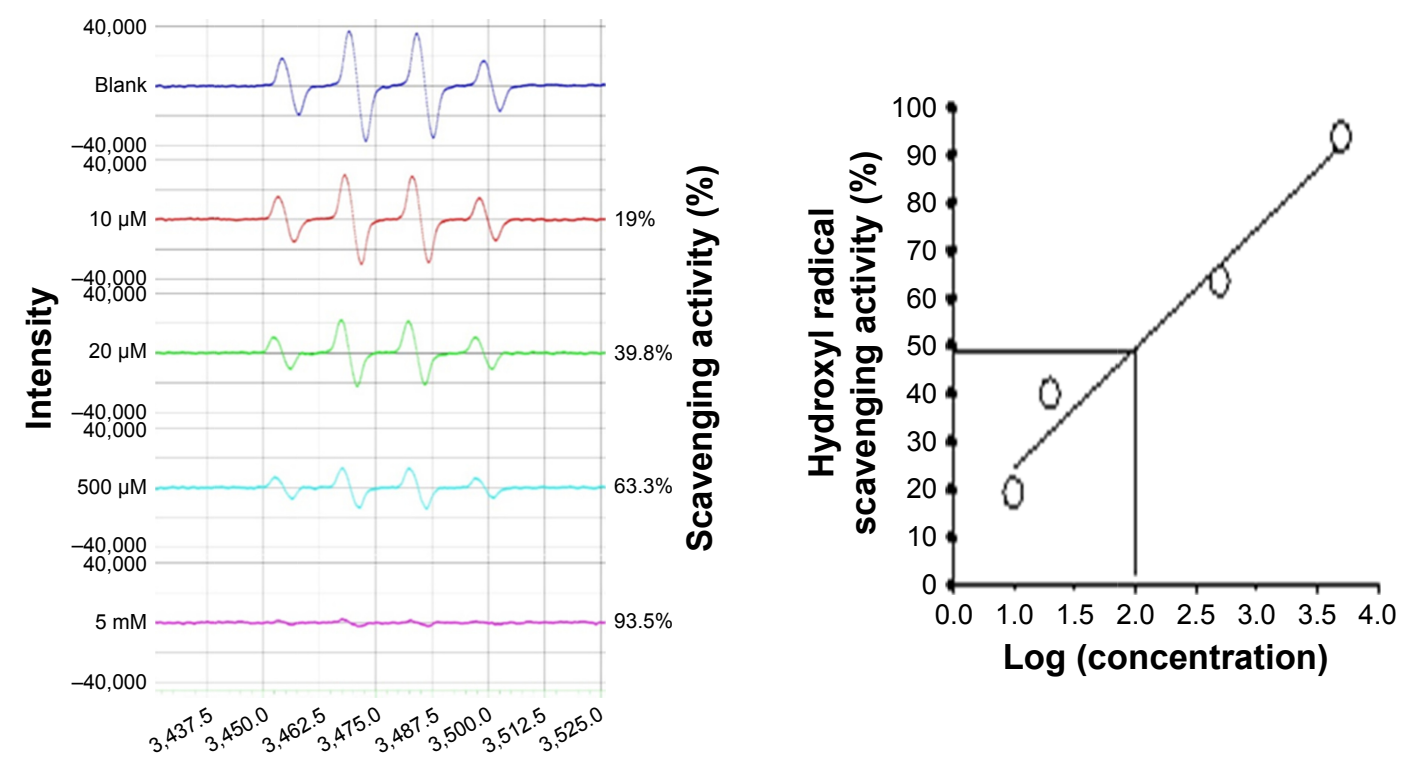

(G)

Figure 3 The radical scavenging activities of acetH.

Notes: (A) Dose-dependent scavenging activities of acetH (6, 12, 24, and $60 \mu \mathrm{M}$ ) against DPPH radicals. Data were mean \pm SD. (B) Dose-dependent scavenging activities of acetH ( $10 \mu \mathrm{M}, 20 \mu \mathrm{M}, 500 \mu \mathrm{M}$, and $5 \mathrm{mM}$ ) against hydroxyl radicals detected by the electron spin resonance spectrometry.

Abbreviations: acetH, acetohydroxamic acid; DPPH, $\alpha, \alpha$-diphenyl- $\beta$-picrylhydrazyl.

\section{Effects of acetH on SSAO inhibitory activities and related kinetic parameters}

Different concentrations of acetH $(5,10,25$, and $50 \mu \mathrm{M})$ were used to investigate the SSAO inhibitory activities (Figure 4A). AcetH was found to show dose-dependent inhibitory activities against SSAO. AcetH at concentrations of $5,10,25$, and $50 \mu \mathrm{M}$ showed SSAO inhibitory activities of $28.4 \%, 54.3 \%, 80.2 \%$, and $94.1 \%$, respectively. The relationships between calculated SSAO inhibitory activities $(\mathrm{Y})$ and the acetH concentrations $(\mathrm{X})$ used were transformed into the equation: $\mathrm{Y}=14.045+3.889 \mathrm{X}-0.046 \mathrm{X}^{2}\left(R^{2}=0.977\right)$. Therefore, the calculated $\mathrm{IC}_{50}$ for the SSAO inhibitory 
A

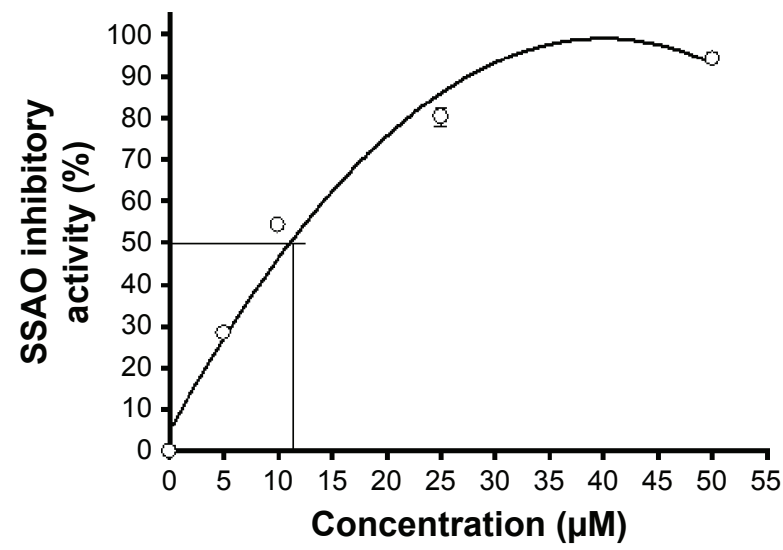

B

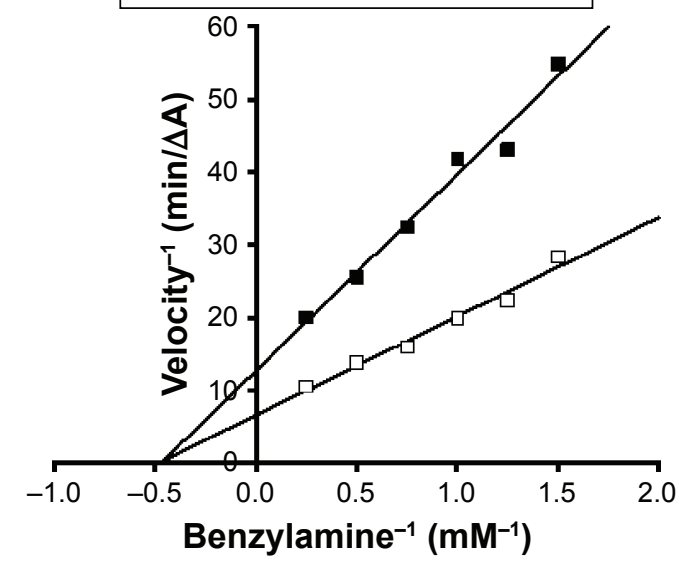

Figure 4 The SSAO inhibitory activities and kinetic properties of acetH.

Notes: (A) Dose-dependent SSAO (2.53 units) inhibitory activities of acetH (5, 10, 25, and $50 \mu \mathrm{M})$. Data were mean \pm SD. (B) The Lineweaver-Burk plots for determining SSAO kinetic parameters in the presence of acetH $(6.5 \mu \mathrm{M})$ using different concentrations of benzylamine as the substrate $(0.67,0.8,1,1.33,2$, and $4 \mathrm{mM})$.

Abbreviations: acetH, acetohydroxamic acid; SSAO, semicarbazide-sensitive amine oxidase.

activity of acetH was $10.56 \mu \mathrm{M}$, which was about onethird of semicarbazide $(34.21 \mu \mathrm{M})$ reported under the same conditions. ${ }^{18}$ Determination of SSAO kinetic parameters in the presence of acetH $(6.5 \mu \mathrm{M})$ showed that $\mathrm{Km}^{\prime}$ was not significantly different from $\mathrm{Km}$; however, Vmax' decreased from $0.1509\left(\Delta \mathrm{A}_{420 \mathrm{~nm}} / \mathrm{min}\right)$ to $0.0785\left(\Delta \mathrm{A}_{420 \mathrm{~nm}} / \mathrm{min}\right)$. AcetH showed noncompetitive inhibition (Figure 4B). The present kinetic results meant that acetH could reduce the maximum catalytic rates of SSAO without altering the affinity of benzylamine toward SSAO. It was reported that $A \beta$ itself could induce SSAO increases in Alzheimer's disease (AD), and the metabolites catalyzed by SSAO might destroy normal vascular function and then accelerate the cerebral amyloid angiopathy related to AD progression. ${ }^{30}$ The soluble SSAO activity might contribute to oxidative stress in streptozotocininduced diabetic rats. ${ }^{31}$

The hydroxamate moiety derivatives have been reviewed for their pharmacologic and biologic activities toward cancer, cardiovascular diseases, AD, tuberculosis, and so on. ${ }^{16}$ Succinimide hydroxamic acids were reported to be potent histone deacetylase inhibitors and show inhibition against tumor cell proliferation. ${ }^{32}$ The salicylic acid derivatives containing hydroxamate moiety were reported to be potent cyclooxygenase- 1 and cyclooxygenase- 2 inhibitors. ${ }^{33}$ Oxal acid derivatives containing hydroxamate moiety were found to be potent matrix metalloproteinase inhibitors. ${ }^{34}$ Few hydroxamate derivatives were reported to be antiglycation agents, and the results of this study showed that both clinical drugs containing the hydroxamate moieties of acetH and $\mathrm{HU}$ to be better than $\mathrm{AG}$ in the reduction of AGE formation.
The self-prepared pectin hydroxamates ${ }^{35,36}$ and alginic acid hydroxamates ${ }^{37}$ in our previous reports exhibited SSAO inhibitory activities and DPPH radical and hydroxyl radical scavenging activities, and both pectin hydroxamates ${ }^{35,36}$ and alginic acid hydroxamates belonged to macromolecular polysaccharides. The self-prepared galacturonic acid hydroxamate $^{38}$ showed DPPH radical scavenging activities with $\mathrm{IC}_{50}$ of $82 \mu \mathrm{M},{ }^{38}$ which was about 2.5 -fold higher than that of acetH in this study; the self-prepared galacturonic acid hydroxamate ${ }^{22}$ showed SSAO inhibitory activities with $\mathrm{IC}_{50}$ of $41 \mu \mathrm{M},{ }^{22}$ which was about 4 -fold higher than that of acetH in this study.

\section{Conclusion}

Results of this study showed that the simple hydroxamic acid derivative of acetH possessed antiglycation activity in vitro, DPPH radial and hydroxyl radical scavenging activities, and dose-dependent SSAO inhibitory activities. AcetH, a bacterial urease inhibitor, is used to treat kidney stones and infections in the urinary tract. AcetH, which might have the potential for the treatment of cardiovascular disease and diabetes complications, needs further investigation in cell and animal models.

\section{Acknowledgment}

The authors would like to thank Shin Kong Wu Ho-Su Memorial Hospital (SKH-TMU-105-08) for the financial support.

\section{Disclosure}

The authors report no conflicts of interest in this work. 


\section{References}

1. Beckman KB, Ames BN. The free radical theory of aging matures. Physiol Rev. 1988;78(2):547-581.

2. Gey KF. The antioxidant hypothesis of cardiovascular disease: epidemiology and mechanisms. Biochem Soc Trans. 1990;18(6):1041-1045.

3. Costin GE, Hearing VJ. Human skin pigmentation: melanocytes modulate skin color in response to stress. FASEB J. 2007;21(4):976-994.

4. Muller FL, Lustgarten MS, Jang Y, Richardson A, Van Remmen H. Trends in oxidative aging theories. Free Rad Biol Med. 2007;43(4): 477-503.

5. Zhang Q, Ames JM, Smith RD, Baynes JW, Metz TO. A perspective on the Maillard reaction and analysis of protein glycation by mass spectrometry: probing the pathogenesis of chronic disease. J Proteom Res. 2009;8(2):754-769.

6. Nagaraj RH, Linetsky M, Stitt AW. The pathogenic role of Maillard reaction in the aging eye. Amino Acids. 2012;42(4):1205-1220.

7. Nagai R, Shirakawa J, Ohno R, Moroishi N, Nagai M. Inhibition of AGEs formation by natural products. Amino Acids. 2014;46(2): 261-266.

8. Calcutt NA, Cooper ME, Kern TS, Schmidt AM. Therapies for hyperglycaemia-induced diabetic complications: from animal models to clinical trials. Nat Rev Drug Discover. 2009;8(5):417-429.

9. Foote EF, Look ZM, Giles P, Keane WF, Halstenson CE. The pharmacokinetics of aminoguanidine in end-stage renal disease patients on hemodialysis. Am J Kidney Dis. 1995;25(3):420-425.

10. He C, Sabol J, Mitsuhashi T, Vlassara H. Inhibition of reactive products by aminoguanidine facilitates renal clearance and reduces tissue sequestration. Diabetes. 1999;48(6):1308-1315.

11. Yamagishi SI, Nakamura K, Matsui T, Ueda S, Noda Y, Imaizumi T. Inhibitors of advanced glycation end products (AGEs): potential utility for the treatment of cardiovascular disease. Cardiovas Ther. 2008;26(1): 50-58.

12. Nagai R, Mori T, Yamamoto Y, Kaji Y, Yonei Y. Significance of advanced glycation end products in aging-related disease. Anti-Aging Med. 2010;7(10):112-119.

13. Jalkanen $\mathrm{S}$, Salmi M. Cell surface monoamine oxidases: enzymes in search of a function. EMBO J. 2001;20(15):3893-3901.

14. Magyar K, Mészárosm Z, Mátyus P. Semicarbazide-sensitive amine oxidase. Its physiological significance. Pure Appl Chem. 2001;73(9): 1393-1400.

15. Wong MYW, Saad S, Pollock C, Wong MG. Semicarbazide-sensitive amine oxidase and kidney disease. Am J Physiol Renal Physiol. 2013; 305(12):F1637-F1644.

16. Muri EMF, Nieto MJ, Sindelar RD, Williamson JS. Hydroxamic acids as pharmacological agents. Cur Med Chem. 2002;9(17):1631-1653.

17. Martelli A, Buli P, Cortecchia V. Acetohydroxamic acid therapy in infected renal stones. Urology. 1981;17(4):320-322.

18. Liu YH, Wu WC, Lu YL, Lai YJ, Hou WC. Antioxidant and amine oxidase inhibitory activities of hydroxyurea. Biosci Biotechnol Biochem. 2010;74(6):1256-1260.

19. Liu YH, Lu YL, Han CH, Hou WC. Inhibitory activities of acteoside, isoacteoside, and its structural constituents against protein glycation in vitro. Bot Stud. 2013;54(1):6.

20. Han CH, Lin YS, Lin SY, Hou WC. Antioxidant and antiglycation activities of the synthesised dipeptide, Asn-Trp, derived from computer-aided simulation of yam dioscorin hydrolysis and its analogue, Gln-Trp. Food Chem. 2014;147:195-202.

21. Lin SY, Wang CC, Lu YL, Wu WC, Hou WC. Antioxidant, antisemicarbazide-sensitive amine oxidase, and anti-hypertensive activities of geraniin isolated from Phyllanthus urinaria. Food Chem Toxicol. 2008;46(7):2485-2492.
22. Liu YH, Huang WJ, Lu YL, et al. Semicarbazide-sensitive amine oxidase inhibitory activity of galacturonic acid hydroxamate. Bot Stud. 2011;52(1):35-40.

23. Burn HF, Higgins PJ. Reaction of monosaccharides with proteins: possible evolutionary significance. Science. 1981;213(4504):222-224.

24. Wu CH, Yen GC. Inhibitory effect of naturally occurring flavonoids on the formation of advanced glycation endproducts. J Agric Food Chem. 2005;53(8):3167-3173.

25. Matiacevich SB, Santagapita PR, Buera MP. Fluorescence from the maillard reaction and its potential applications in food science. Crit Rev Food Sci Nutr. 2005;45(6):483-495.

26. Thornalley PJ. Use of aminoguanidine (pimagedine) to prevent the formation of advanced glycation endproducts. Arch Biochem Biophys. 2003;419(1):31-40.

27. Assar SH, Moloney C, Lima M, Magee R, Ames JM. Determination of $\mathrm{N}^{\varepsilon}$-(carboxymethyl)lysine in food systems by ultra performamce liquid chromatography-mass spectrometry. Amino Acids. 2009;36(2): 317-326.

28. Hashimoto C, Iwaihara Y, Chen SJ, Tanaka M, Watanabe T, Matsui T. Highly-sensitive detection of free advanced glycation endproducts by liquid chromatography-electrospray ionization-tandem mass spectrometry with 2,4,6-trinitrobenzene sulfonate derivatization. Anal Chem. 2013;85(9):4289-4295.

29. Kayyali R, Pannala AS, Khodr H, Hider RC. Comparative radical scavenging ability of bidentate iron (III) chelators. Biochem Pharmacol. 1998;55(8):1327-1332.

30. Solé M, Miñano-Molina AJ, Unzeta M. A cross-talk between A $\beta$ and endothelial SSAO/VAP-1 accelerates vascular damage and A $\beta$ aggregation related to CAA-AD. Neurobiol Aging. 2015;36(2):762-775.

31. Somfai GM, Knippel B, Ruzicska É, et al. Soluble semicarbazidesensitive amine oxidase (SSAO) activity is related to oxidative stress and subchronic inflammation in streptozotocin-induced diabetic rats. Neurochem Internal. 2006;48(8):746-752.

32. Curtin ML, Garland RB, Heyman HR, et al. Succinimide hydroxamic acids as potent inhibitors of histone deacetylase (HDAC). Bioorg Med Chem Lett. 2002;12(20):2919-2923.

33. Dooley CM, Devocelle M, McLoughlin B, Nolan KB, Fitzgerald DJ, Sharkey CT. A novel family of hydroxamate-based acylating inhibitors of cyclooxygenase. Mol Pharmacol. 2003;63(2):450-455.

34. Krumme D, Tschesche H. Oxal hydroxamic acid derivatives with inhibitory activity against matrix metalloproteinases. Bioorg Med Chem Lett. 2002;12(6):933-936.

35. Hou WC, Lee MH, Hsu FL, Lin YH. Inhibitory activities of semicarbazide-sensitive amine oxidase and angiotensin converting enzyme of pectin hydroxamic acid. J Agric Food Chem. 2003;51(21): 6362-6366.

36. Yang SS, Cheng KD, Lin YS, Liu YW, Hou WC. Pectin hydroxamic acid exhibited antioxidant activities in vitro. J Agric Food Chem. 2004;52(13):4270-4273.

37. Liu DZ, Wu WC, Liang HJ, Hou WC. Antioxidant and semicarbazidesensitive amine oxidase inhibitory activities of alginic acid hydroxamates. J Sci Food Agric. 2007;87(1):138-146.

38. Liu YH, Lin SY, Lee CC, Hou WC. Antioxidant and nitric oxide production inhibitory activities of galacturonyl hydroxamic acid. Food Chemistry. 2008;109(1):159-166. 


\section{Publish your work in this journal}

Drug Design, Development and Therapy is an international, peerreviewed open-access journal that spans the spectrum of drug design and development through to clinical applications. Clinical outcomes, patient safety, and programs for the development and effective, safe, and sustained use of medicines are the features of the journal, which has also been accepted for indexing on PubMed Central. The manuscript management system is completely online and includes a very quick and fair peer-review system, which is all easy to use. Visit http://www.dovepress.com/testimonials.php to read real quotes from published authors.

Submit your manuscript here: http://www.dovepress.com/drug-design-development-and-therapy-journal 